\title{
THE TENSOR FASCIAE LATAE FLAP AND ITS USE IN THE CLOSURE OF TROCHANTERIC AND ISCHIAL PRESSURE SORES
}

\author{
By J. C. McGregor, F.R.C.S. and A. C. Buchan, F.R.C.S. \\ Bangour General Hospital, West Lothian and Edenhall Hospital, \\ Musselburgh, Scotland
}

\begin{abstract}
Trochanteric and ischial pressure sores were treated by excision and repair by the tensor fasciae latae myocutaneous flap. The results and anatomical basis are discussed.
\end{abstract}

Key words: Myocutaneous flap; Closure of trochanteric and Ischial pressure sores.

\section{Introduction}

TROCHANTERIC and ischial pressure sores are probably the most frequent of all sores to be encountered in the paraplegic patient. Conway and Griffith (1956) recorded 44 per cent in a large series to be either ischial or trochanteric sores. Although it is possible to obtain healing by conservative methods, in our experience this can be a very slow process and by no means certain of success, especially in the more extensive and recurrent lesions. It has for some time now been the practice in our hospitals to adopt a more active surgical approach to the problem. A variety of procedures have been performed including skin grafting, direct closure, and flaps. The flaps are usually rotation or transposed flaps consisting of skin and subcutaneous tissue and not based on any particular named vascular pedicle. They are thus random pattern flaps, the safety and design of which is considerably more limited than the axial pattern flap (McGregor and Morgan, 1973). An axial pattern flap receives its blood supply through a direct cutaneous artery and is drained by accompanying veins. The artery lies in the subcutaneous tissue above the underlying muscle layer. Unfortunately, in the trochanteric and ischial regions, no suitable axial pattern flaps are available.

In the last few years, however, it has become increasingly apparent that the safety and blood supply to skin flaps can be improved by incorporation of the underlying muscle with the skin and subcutaneous tissue. Owens (1955) was probably the first to describe the use of such a compound flap using sternomastoid muscle and overlying skin to repair defects in the face. He possibly failed to realise the value of the contribution to the blood supply to this compound flap from the musculocutaneous perforating vessels which renders such a flap much safer than a random flap. Since then, there has developed an increasing understanding of such an arrangement and many musculocutaneous flaps have been described. McCraw et al. (1977) have investigated the vascularity and anatomical features of a large number of such flaps. The basic differences between a random, axial pattern and musculocutaneous flap are illustrated diagrammatically (Fig. I).

One musculocutaneous flap which they do not describe and has to date received little publicity is the Tensor Fasciae Latae Myocutaneous Flap. Almost certainly Bailey in 1967 was the first to use the tensor fasciae latae muscle with overlying thigh skin in filling in the gap in the acetabulum after excising the hip 
(1)

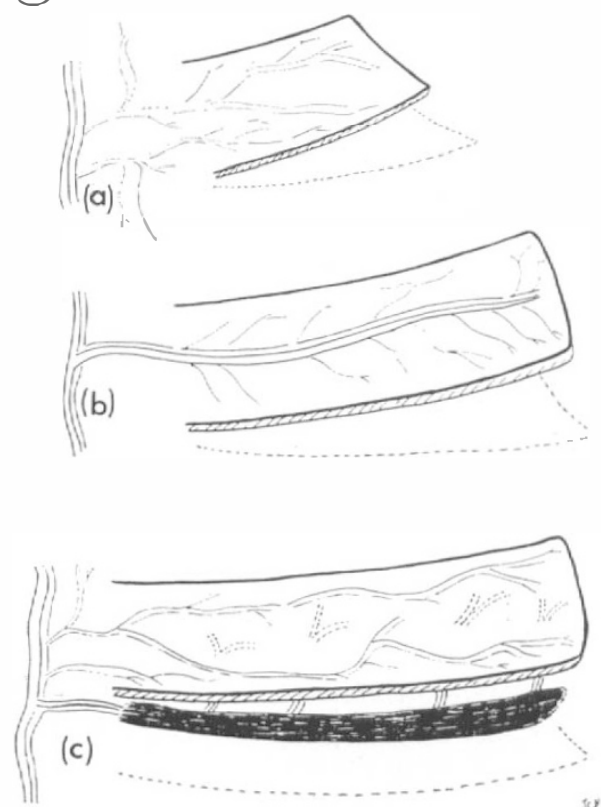

(2)

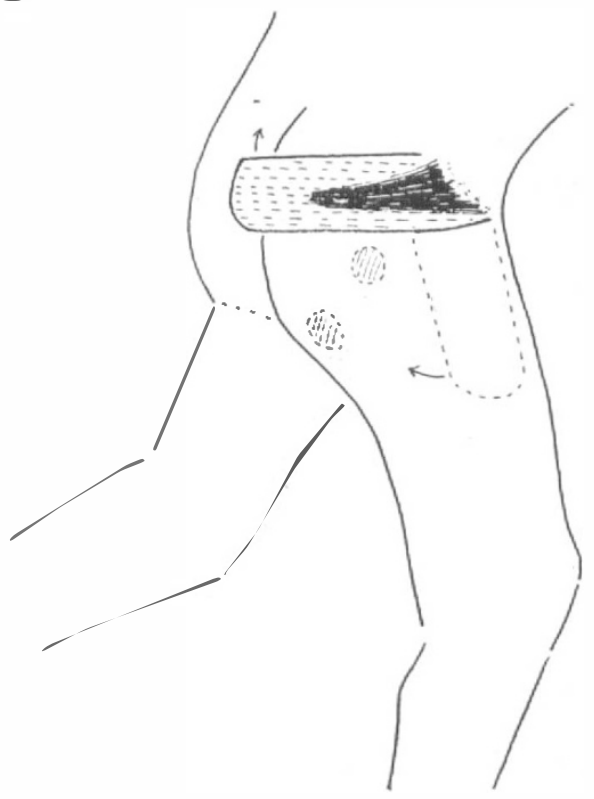

FIG. I

Diagram to illustrate the differences between a random pattern flap (a), an axial pattern flap (b), and a musculo-cutaneous flap (c). The axial pattern flap, being supplied by large axial vessels, can be raised safely to a greater length than the flap supplied randomly. By adding the underlying muscle to either $(a)$ or $(b)$, a larger flap can be devised.

FIG. 2

Diagram to illustrate the posterior arc of rotation of the flap. The shaded circles represent trochanteric and ischial pressure sores.

joint. However, the use of this compound flap for treatment of ischial and trochanteric pressure sores was described only recently (Nahai et al., I978).

We learned about this technique in 1978 prior to publication of their findings and decided to investigate the flap in our patients.

\section{Anatomy}

The tensor fasciae latae muscle originates from the anterior outer surface of the iliac crest and deep surface of the fascia lata. It is a flat muscle of variable length but fairly broad. The blood supply has been studied by Hill et al. (1978). The arterial supply is a transverse branch of the lateral femoral circumflex artery which emerges between vastus lateralis and the rectus femoris. Venous drainage is given by one of a pair of venae comitantes of the transverse branch of the lateral femoral circumflex artery. The vascular pedicle enters the muscle approximately $6 \mathrm{~cm}$ distal to the anterior iliac crest.

Figure 2 demonstrates the arc capable of being covered by transposing such a flap posteriorly. It can be seen that this flap can be used to treat ischial, trochanteric and possibly some sacral sores. 


\section{Method}

Before any surgical closure, general medical care is given to improve the patient's general condition and reduce any local sepsis. Figures 3-5 demonstrate the initial marking of the flap, elevation and subsequent insertion as used for closure of an ischial sore. For the closure of a trochanteric sore, a shorter flap is used but for both the same basic procedure is performed. Dissection begins distally and the fascia lata is divided level with the distal skin incision. It is then elevated with the flap by extending the incisions proximally along the lateral margins of the proposed flap. To prevent the separation of the fascia lata and superiorly attached tensor muscle, it is useful to stitch the lower free end of the fascia lata to the subcutaneous tissue of the flap. The elevation of the compound flap is quickly and easily performed thereafter. The flap is directed into the excised pressure sore defect and
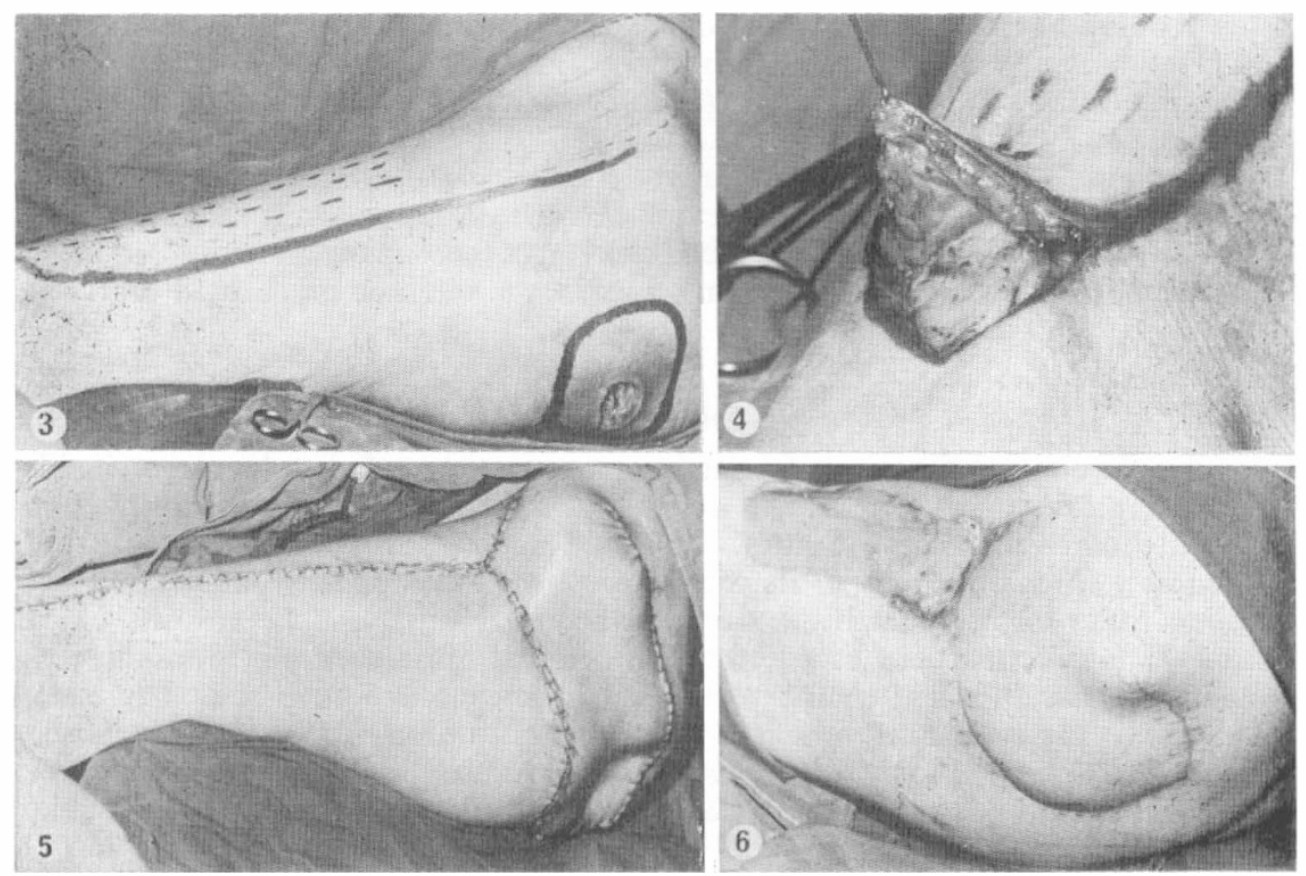

FIG. 3

Pre-operative marking of a long flap and ischial sore with undermined area to be excised. The flap is seen just proximal to the knee. Flap width is determined by width of defect to be covered.

FIG. 4

Raising of the flap begins at the distal end and continues in depth through the subcutaneous fat to the level of the white fibres of the fascia lata.

FIG. 5

The flap has been sutured in place without tension and the donor area in the thigh has been closed without grafting.

FIG. 6

Split skin graft was required to close this donor area, unable to be closed directly. The flap had been used to close a trochanteric sore. 
sutured in place. In nearly every case, the donor area in the thigh is capable of being directly closed under moderate tension. Where this is not so, split skin grafting requires to be performed (Fig. 6). Any bone prominence has of course been excised prior to inset of the flaps.

\section{Results}

Twelve paraplegic patients have been operated upon with a total of 15 flaps. Thirteen trochanteric and two ischial sores have been treated (in three patients the trochanteric sores were bilateral). Direct closure of the defect in the thigh caused by elevation of the flap was possible in all except three. In one of these, the problem appeared to be due to excessive tissue rigidity associated with ectopic calcification, while in the other two, previous surgical procedures appeared to have produced a reduction in tissue laxity for direct closure.

Healing of these flaps and the donor areas proceeded rapidly. No loss has occurred although a small terminal portion of the flap necrosed in both instances when it was used to close an ischial sore. Subsequent direct closure of these was possible.

It should be pointed out that in the majority of the patients in this series, multiple surgical procedures had previously been performed to try and close the sores in question. Due to acute bed shortages and many patients requiring admission, prolonged conservative in-patient care was not practicable for large sores.

\section{Discussion}

We have found the tensor fasciae latae myocutaneous flap to be very valuable in the surgical management of the ischial and trochanteric pressure sore, though probably more reliable in the latter. Not only is it easy to design and elevate, but its safety (which is related to its muscular-vascular component) and rapidity of healing make for considerably easier post-operative nursing. Because its blood supply is to a large extent based on the underlying muscle and not the skin, it is possible to use this flap in the presence of previous operative skin flap scars. Conversely, the breakdown of such a flap would not necessarily prevent the design of an alternative flap. Finally, as pointed out by Nahai et al. (I978), it is possible to use the flap to close co-existing trochanteric and ischial sores on the same side.

\section{SUMMARY}

Trochanteric and ischial pressure sores can be treated conservatively. There are various surgical procedures that can be attempted. The Tensor Fasciae Latae Flap is a new surgical approach to the problem. We have used this flap in a number of cases and propose to describe the anatomical basis and its use in the clinical situation.

\section{RÉSUMÉ}

Le lambeau Tensor Fasciae Latae et son utilisation dans la fermeture des escarres (de compression).

Les escarres peuvent être traitées de façon conservatrice. On peut essayer de diverses procédés chirurgicaux. Le lambeau Tensor Fasciae Latae représente un nouvel abord chirurgical au problème. Nous avons utilisé ce lambeau dans plusieurs cas et proposons décrire sa base anatomique et son utilisation dans la situation clinique. 


\section{ZUSAMMENFASSUNG}

Der Tensor Fasciae Latae Flap ist eine neue chirurgische Methode zu dem Problem. Wir haben diesen 'Flap' in mehreren Fällen angewandt. Wir beschreiben die anatomische Grundlage und seinen Gebrauch in der klinischen Behandlung von Druckgeschwürch des Trochanter.

\section{REFERENCES}

BaIley, B. N. (1967). Bedsores, p. I13. Edward Arnold (Publishers) Ltd., London.

Conway, H. \& GRIFFith, B. H. (I956). Plastic Surgery for closure of decubitus ulcers in patients with paraplegia based on experience with 1000 cases. Am. F. Surgery, 91, 946-975.

Hill, H. L., Nahai, F. \& Vasconez, L. O. (I978). The tensor fascia lata myocutaneous free flap. Plastic and Reconst. Surgery, 61, 517-52I.

McCraw, J. B., Dibbell, D. G. \& Carraway, J. H. (1977). Clinical definition of independent myocutaneous vascular territories. Plastic and Reconstr. Surg., 60, 34I-352.

McGregor, I. A. \& Morgan, G. (1973). Axial and random pattern flaps. Brit. F. Plast. Surg., 26, 202-213.

Nahai, F., Silverton, J. S., Hill, H. L. \& Vasconez, L. O. (1978). The tensor fascia lata musculocutaneous flap. Annals of Plastic Surgery, I, 372-379.

OWENs, N. (1955). Compound neck pedicle designed for the repair of massive facial defects; formation, development and application. Plastic and Reconstr. Surg., 15, 369-389. 